St. Catherine University

SOPHIA

Library Staff Publications

University Library

2014

\title{
Situating Information Literacy Within the Curriculum: Using a Rubric to Shape a Program
}

Heather Tompkins

St. Catherine University, hltompkins@stkate.edu

Iris Jastram

Carleton College, ijastram@carleton.edu

Danya Leebaw

Carleton College,dleebaw@carleton.edu

Follow this and additional works at: https://sophia.stkate.edu/lib

Part of the Information Literacy Commons

\section{Recommended Citation}

Jastram, Iris, Danya Leebaw, and Heather Tompkins. "Situating Information Literacy Within the Curriculum: Using a Rubric to Shape a Program," Portal 14 (2014): 165-186.

This Article is brought to you for free and open access by the University Library at SOPHIA. It has been accepted for inclusion in Library Staff Publications by an authorized administrator of SOPHIA. For more information, please contact amshaw@stkate.edu. 


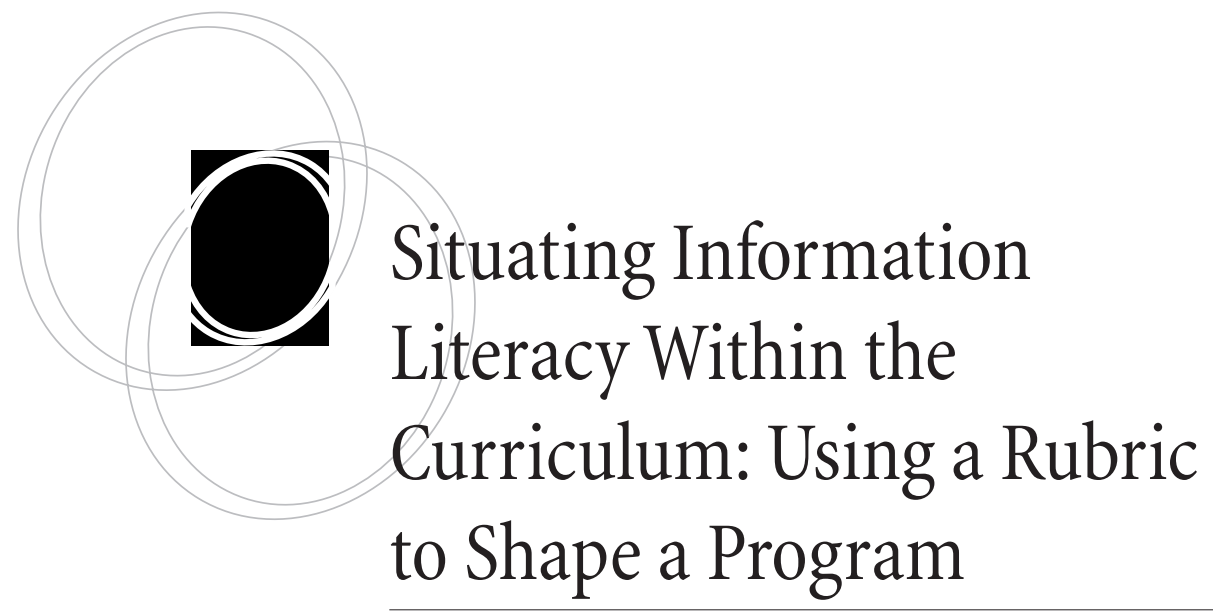

Iris Jastram, Danya Leebaw, and Heather Tompkins

abstract: Rubrics are a rapidly growing subfield of information literacy assessment, providing a powerful tool for understanding student learning. This paper explores the role that the creation and application of an information literacy rubric can play in program development. Because of the Information Literacy in Student Writing assessment project at Carleton College, opportunities for information literacy instruction have opened up, we have begun the long process of arriving at a shared understanding of information literacy on campus, and our information literacy program is better integrated with campus-wide goals.

\section{Introduction}

7 he words "assessment" and "rubric" connote activities that might seem remote from the core work of the instruction librarian. Large-scale assessment projects,

in particular, can take months or even years to complete, and it is often difficult to predict how useful the results will be. But what if the development of the assessment project could itself tap into librarians' curiosity about their students, into librarians' teaching goals, and even into the meaning of information literacy itself? What if the assessment project itself-findings aside-helps to develop and strengthen an information literacy program? What if findings about undergraduate learning help to articulate a concept of information literacy that resonates with teaching faculty across the campus? And what if the act of carrying out the project inspires campus conversations about the ways in which information literacy is inherently intermingled with the values and conventions of many different fields of study? These results have been the experience at Carleton College, a small liberal arts college in Minnesota, as the Reference \& Instruction 
Department at the Laurence McKinley Gould Library has embarked on the Information Literacy in Student Writing (ILSW) project. We developed a rubric for reading papers in many genres and many academic disciplines - that is, a set of guidelines for rating per-

What if the assessment project itself-findings aside-helps to develop and strengthen an information literacy program? formance that stated expectations and described levels of quality from excellent to poor. We used that rubric to stir imaginations and spark creativity in information literacy experiences across the curriculum. In addition to gaining useful insights into our students' skills, we also reaped unexpected rewards from this assessment project, including a deeper articulation of

information literacy goals for our library and our campus. We aim to add to the growing literature on the assessment of information literacy by focusing less on undergraduate performance and more on how the actual development of an information literacy rubric for campus-wide use is advancing our goals.

\section{Situating Ourselves Within the College's Values}

Carleton's culture has two characteristics that contribute to the shape of our project. First, there is a long tradition of cross-departmental, grassroots discussion about teaching and learning. Nearly all of these discussions have developed through a combination of informal conversations, a standing series of well-attended lunch presentations put on by the Perlman Center for Learning and Teaching, and faculty development workshops. Some discussions coalesce into formal curricular initiatives and programs, such as Writing Across the Curriculum (WAC); Visual Literacy (Viz); and Quantitative Inquiry, Reasoning, and Knowledge (QuIRK). These discussions and initiatives are powerful vehicles for faculty development and curricular change at Carleton. Interestingly, many initiatives have an assessment project as one of their core activities. The projects that seem to produce the most curricular impact have been those that, like our ILSW project, have used assessment less as a way of quantifying outcomes and more as a way of standardizing expectations around shared motivating values on campus, a process referred to as "norming" in the literature on assessment. Two motivating values, in particular, stand out: inquisitiveness and a belief in the effectiveness of autonomous educators who share a goal of sparking deeply engaged thinking and learning in our students. ${ }^{1}$

Embedded in that shared and unifying goal is a phrase that has gained significant traction at Carleton in recent years: "habits of mind." This phrase has come to embody many aspects of a liberal arts education, in which disparate but interrelated academic experiences foster an instinct to think critically and communicate effectively. ${ }^{2}$ It is for this reason that our graduation requirements include, for example, "quantitative reasoning encounters" rather than requiring full courses devoted to quantitative skills. "Quantitative reasoning" refers to the ability to understand information presented in mathematical terms - for example, graphs, charts, tables, or changes in percentage-and knowing how to use that information to support one's own arguments and evaluate those of others. The college ensures that students will have opportunities to encounter quantitative reasoning in a variety of assignments, courses, and departments with the goal of building quantitatively adept habits of mind. ${ }^{3}$ 
Given this culture and these values, librarians at Carleton have found that actively participating in curricular initiatives and in faculty development events is a powerful mechanism for influencing the curriculum. These activities are where we hear about new courses, help faculty determine what resources are available to support specific assignments, share our campus-wide perspective of students, and brainstorm with faculty about what information literacy components could be involved in assignments, courses, and majors.

Enacting Rolf Norgaard's philosophy of "situated" information literacy has also allowed us to participate in and learn from other major assessment projects on campus. ${ }^{4}$ WAC coordinates the collection and scoring of the sophomore writing portfolios (submissions are a graduation requirement), and various groups on campus then use these portfolios to gain insight into sophomore abilities. The curricular initiative on which we have most modeled our own, QuIRK, uses the portfolios to assess students' quantitative habits of mind, reading papers against a rubric of quantitative literacy dimensions. ${ }^{5}$ Both WAC and QuIRK use their as-

We believe other librarians ... will find this approach of building from, and embedding projects into, existing curricular projects succeeds on their campuses as well. sessment projects and the attendant discussions and workshops to spark the faculty's imagination and to norm expectations curriculum-wide. We have used the work done by WAC and QuIRK to intentionally integrate ourselves into their related initiatives, and we built our assessment project on the QuIRK model. We believe other librarians, particularly those at small liberal arts colleges, will find this approach of building from, and embedding projects into, existing curricular projects succeeds on their campuses as well.

\section{Merging Campus Values and Information Literacy Assessment}

Apart from informally weaving information literacy into existing campus initiatives, the library has been developing a more formal information literacy program-one that includes assessment-for many years. We first began to articulate information literacy goals as one outcome of an Andrew W. Mellon Foundation Information Literacy grant in 2000, producing, among other things, white papers on best practices in information literacy. Beginning in 2003, together with faculty and institutional research staff at several liberal arts colleges, we designed the Research Practices Survey (RPS) to assess first-year students' attitudes, behaviors, skills, and beliefs about research. Despite many important findings, the RPS left us curious to know more about our students. The RPS is a fixedchoice test that, while lending valuable insights, still has inherent limitations. We wanted to round out our learning from RPS with other projects to deepen our understanding of how students apply information literacy skills in the context of real coursework.

We are by no means the first to integrate assessment into our information literacy efforts. In 1989, the American Library Association (ALA) formalized the use of the term "information literacy" in its Presidential Committee on Information Literacy: Final Report. ${ }^{6}$ Then in 2000, the Association of College and Research Libraries (ACRL) issued its In- 
formation Literacy Competency Standards for Higher Education. ${ }^{7}$ The ACRL Standards mandated assessment of learning outcomes but left the methods up to individual libraries. ${ }^{8}$ Sparked by these national standards and further pushed by regional accrediting agencies, librarians have made significant strides in articulating information literacy learning goals for their individual campuses and students. ${ }^{9}$

Libraries have also carried out several imaginative and informative projects to gain a better understanding of student research behavior. Project SAILS (Standardized Assessment of Information Literacy Skills), begun in 2001 at Kent State University in Ohio, uses a standardized online test to measure information literacy skills and identify areas for improvement. Project Information Literacy, started at the University of Washington's Information School in Seattle in 2008, is a national study that analyzes how students find information and conduct research for their coursework and for their everyday lives. The Undergraduate Research Project, begun in 2004 at the University of Rochester in New York, used anthropological techniques to study undergraduates and their use of information. The project employed photographs, ethnographic videos, mapping exercises, and interviews to collect data. ${ }^{10}$

Rubrics are currently a small but growing subfield of information literacy assessment. ${ }^{11}$ From the literature, we find that most information literacy rubrics are mapped in

\section{Librarians have found that undergraduates struggle less with citation mechanics and more with the conceptual basis and implications of attribution.}

some way to the ACRL Standards, often with some relevant course or program modification, and that the rubrics are often created in collaboration with faculty and other stakeholders on

campus. ${ }^{12}$ This kind of collaboration has the potential not only to improve the instrument but also to help all participants arrive at shared information literacy goals through productive dialogue about the core values that

Apparently, students need the most help with the concepts behind information literacy rather than with the skills those concepts demand. ground the rubric. ${ }^{13}$ Many rubric projects, as described in the literature, have led to important insights into students' abilities. For example, librarians have found that undergraduates struggle less with citation mechanics and more with the conceptual basis and implications of attribution. And while locating sources is often easy for students, determining the relevance of sources and synthesizing them into a rhetorical claim is a far greater challenge. Apparently, students need the most help with the concepts behind information literacy rather than with the skills those concepts demand. And this need for help, in turn, has implications for how librarians teach information literacy and what learning goals they set for their interactions with students. ${ }^{14}$

The rubric that we developed merges our community's values and our curiosity regarding how information literacy manifests itself in different disciplines. Like WAC and QuIRK in their respective domains, we wanted to help our campus develop shared goals for information literacy, to learn what our students are good at and what they 
struggle to accomplish, and to help ourselves and our faculty understand what it looks like to meet those goals across the curriculum. We also realized early in our process that a rubric paired with a broad sample of undergraduate writing would help us explore information literacy in a different way than we could do before.

Indeed, rubrics align well with a philosophy of information literacy as more than a discrete set of skills. Rubrics function as constructivist assessment in that they acknowledge the holistic context of the production of knowledge rather than focusing on discrete skills, and they are flexible instruments that help us note trends across a diverse sample of student work. ${ }^{15}$ In other words, they allow readers to discern students' underlying beliefs about the function of source information in rhetoric within the cultural context of written coursework. Reading papers through the lens

Reading papers through the lens of a rubric helps reviewers clearly see how the writers map out information for their readers, build a case for the relevance of particular sources, and integrate external ideas into their own writing. of a rubric helps reviewers clearly see how the writers map out information for their readers, build a case for the relevance of particular sources, and integrate external ideas into their own writing. In this way, rubrics meet Grant P. Wiggins's criteria for a "thoughtful assessment system" in that they "seek evidence of worthy habits of mind."16

\section{Rubric Methodology}

The rubric project we discuss is an ongoing project that began five years ago and is still under development. At this time, we have conducted five readings, four with librarians scoring papers and one, in 2011, in which faculty participated with the support of the college. Two main sources informed the initial design of the rubric and scoring sheets: examples of rubrics and the questions raised by our data from the Research Practices Survey. Since other librarians were already using rubrics for information literacy assessment, we looked at samples to determine best practices. On our own campus, QuIRK provided us with concrete examples of using papers from the sophomore writing portfolios, previously used to evaluate individual students' writing abilities, as a vehicle for evaluating a specific habit of mind across a student cohort. ${ }^{17}$

The questions we investigated initially grew out of the RPS about our students' skills and habits. For example, faculty and librarians were interested in results indicating that a majority of our students were confused about whether or not popular newsmagazines, such as Time and The Atlantic, were scholarly sources. We wanted to build on these results to explore further the nuances of how students make decisions about the sources they use. Did they know, for instance, when it was appropriate for them to draw on newspaper articles and when not? Did they understand how to frame sources? Our

\section{A majority of our students were confused about whether or not popular newsmagazines, such as Time and The Atlantic, were scholarly sources.}


analysis of these survey results, along with the sample rubrics, gave us a framework for thinking about the characteristics we truly wanted to, or even could, assess.

Getting access to student writing can be a barrier that librarians face when doing rubric assessment. Using an existing source of undergraduate work, especially one for which students have already granted permission for use in research, was key to our project. We were fortunate to have a body of student work in the Sophomore Writing Portfolios that was available to us. At Carleton, all sophomores submit a writing portfolio at the end of the year. This portfolio includes representative samples from across the various academic areas in which students must take courses to meet the college's distribution requirements. Portfolios average between four and five papers per student, and undergraduates can (and usually do) permit their portfolios to be used in research. A mixed group of faculty and staff evaluate these portfolios in early summer.

Once the Writing Program and the Office of Institutional Research and Assessment finish assessing these portfolios, we take a stratified random sample of the portfolios marked for use in research-that is, we divide the portfolios into distinct strata, or subgroups, and then select samples from each stratum on the basis of pure chance, using procedures that are as free as possible from built-in bias. We use this sample for our ILSW project. With the exception of 2011, when we read with faculty, our sample in the last three years has grown to include 125 papers per reading, or about 25 percent of the overall population of portfolios each year. Currently, our Office of Institutional Research and Assessment gives us a list of students that mirror the overall demographics of the portfolios submitted, including a representative sample of students whose work falls within the three scored categories: pass, exemplary, and needs work. From each portfolio, we sample one paper to be read in the assessment. These papers are selected arbitrarily, aiming for roughly the same number of papers from each academic division, about 20 percent each from the sciences, social sciences, humanities, arts and literature, and first-year seminars. We do not sample papers according to whether or not a librarian has worked with the course.

Our rubric, which is reproduced here in the Appendix, has three dimensions of information literacy that can be assessed productively in student writing across the curriculum: attribution (Do the writers demonstrate that they understand the purposes of attribution?); evaluation of sources (Do they select evidence that matches the rhetorical purpose of their writing?); and communication of evidence (Do they use information in the service of their own rhetorical goals rather than surrendering the main thrust of the paper to the ideas of others?). Within each dimension, we define a range of mastery on a four-point scale, with 1 designating lack of proficiency and 4 indicating sophisticated mastery. We provide extensive examples within the rubric to help readers identify and assign appropriate scores. In addition to the rubric itself, we use a scoring sheet with detailed definitions of the dimensions. Borrowing from our QuIRK models, we include a list of "illustrative" issues, such as "sources lack breadth or depth," "over/ under cited claims," "egregious errors in bibliography, in-text citations, notes," and "inappropriate source(s) used to support claim." Finally, in addition to the rubric and scoring sheet, we employ group sessions establishing norms to help us achieve high reliability from reader to reader. ${ }^{18}$ 
Shortly after initiating this project, and once we had evaluated a small sample of papers using this rubric, we began to frame our assessment project as investigating information literacy habits of mind rather than simple skills. This understanding arose following intense discussions about which aspects of information literacy we saw appearing in those papers that did not bring in secondary sources. That is, we could see a writer matching evidence to argument even in a paper

We began to frame our assessment project as investigating information literacy habits of mind rather than simple skills. that did not involve "research." A close reading of a literary text, for example, could be evaluated for information literacy if there was an indication that the student needed to select specific pieces of evidence from an overall work to make an argument, or needed to put together particularly fruitful primary sources to make a claim. Similarly, laboratory reports do not always make use of secondary literature. Yet these reports could be evaluated for information literacy when students demonstrated selection and evaluation of evidence to make claims. These realizations contributed to increased nuance in the rubric and broadened our articulations of the place of information literacy within the curriculum. A "habits of mind" framework enabled us to develop and apply the rubric to many kinds of papers.

Critically, the assignments that resulted in these sophomore papers may or may not have directly prompted students to demonstrate information literacy proficiency. In addition, the writers may or may not have submitted the assignment with their portfolios. Most writing, however, benefits from these intellectual habits and leaves clues to them within the rhetoric. The combination of a wide range of papers and a rubric to guide our readings therefore enables us to watch for information literacy habits in an authentic context, a context in which specific competencies are not necessarily directly assigned but are important nonetheless. ${ }^{19}$

As we work with the rubric over time, we regularly revise it to make the dimensions and criteria easier for readers, especially nonlibrarians, to apply consistently. Important questions come up during the readings that are useful to reflect upon. For example, were some assignment types difficult to score, and what was particularly useful or difficult about the criteria for specific skill levels? We have also conducted a set of usability tests with faculty in various departments, taking care to include junior and senior faculty and representatives from the four divisions of the college (natural science, social science, humanities, and arts and literature). All of this discussion and testing has allowed Our rubric not only has become a stronger assessment instrument but also has helped us to deepen our own understanding of information literacy and to refine our articulation of meaningful information literacy goals. us to tighten and refine the scale on our rubric, to make it easier to understand, and to be both flexible and specific enough to be useful across disciplines. ${ }^{20}$ Through this process of repeated revision, our rubric not 
only has become a stronger assessment instrument but also has helped us to deepen our own understanding of information literacy and to refine our articulation of meaningful information literacy goals.

In its current form, our rubric shares characteristics with other information literacy rubrics, but it also diverges in several key ways. First, while we drew on our knowledge

\section{We intentionally developed a rubric that is flexible enough to use across our college's programs and departments.}

of the ACRL Standards, we did not map directly to these standards as many other assessment projects do. ${ }^{21}$ Rather, we chose to develop our rubric organically, grounded in the characteristics we could identify in our early samples of student writing. Some other information literacy rubrics are designed to address one particular dimension or to assess work within a single program or department. ${ }^{22}$ We intentionally developed a rubric that is flexible enough to use across our college's programs and departments. We believe that the cautious, comprehensive, "from the ground up" approach we have taken to developing our rubric has led to its ease of use, meaningful application, and campus acceptance.

\section{Project Outcomes: Anticipated and Otherwise}

Perhaps not surprisingly, there have been anticipated and unanticipated outcomes of the ILSW project. One of the anticipated outcomes is our increased understanding of student strengths and weaknesses. Later in this article we discuss what we learned about the student cohort whose work we analyzed with faculty in 2011. We then explain the implications these findings have for our teaching and our information literacy program.

\section{Attribution}

Students are generally successful when attributing evidence formally in their written work. They are able to cite sources when they are conscious that such citation is their task and when they are given explicit instructions. Although readers noted a handful of "egregious citation errors" on the scoring sheets, a mean score of 2.79 out of 4 across all papers suggests that students' abilities to attribute their sources do not significantly interfere with their goals for communication.

Students can generally follow style guidelines when they incorporate a quotation or a footnote and when they write a reference list. However, the most common issue noted on scoring sheets was over- and under-citation of claims. This finding suggests that students

\section{The most common issue noted} on scoring sheets was over- and under-citation of claims. often attribute uncritically, accomplishing the task of formulating citations but not demonstrating awareness of the purpose for using sources in the first place. Reader comments included: "A lot of claims without evidence"; "Many sources not cited"; "Impossible to tell what sources are used"; "Does not offer evidence for all assertions"; "Overciting-does not use own voice"; and "Overcites in methodology." At the sophomore level, students 


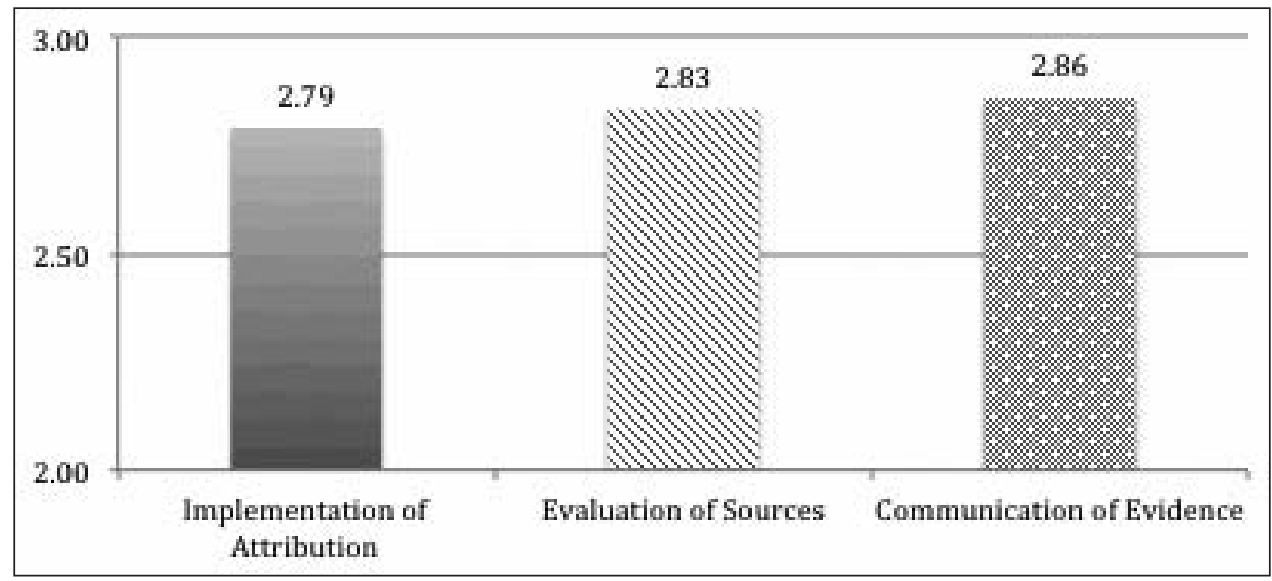

Figure 1. Mean scores

do not yet view citation within the broader context of attribution as a persuasive toolsomething that is critical to argument and signals credibility both of the author and of the author's sources. This finding confirms our suspicion that many sophomores have not yet mastered critical attribution of evidence.

\section{Evaluation of Sources}

We saw that students' abilities to evaluate and select sources can be assessed across disciplines and assignment types. Even in assignments that do not call for outside sources, the writers of papers use information literacy skills to make source decisions, employing what they have learned from course readings or primary sources. Findings in the evaluation dimension suggest that the majority of sophomores are often successful but not yet sophisticated and independent in their approach to selecting sources, scoring a mean of 2.83 out of 4 . Almost a quarter of students (22 percent) managed to employ sources adeptly, scoring a 4 in this dimension. For the majority of papers (59 percent), sources were sometimes inappropriate or even absent when clearly necessary (scoring 3, 2, or 1). According to reader comments, this group of students "missed obvious avenues" of research or "relied on too few sources." For 19 percent of the papers read, this dimension was not applicable.

Students demonstrating mastery in the evaluation of sources shared the ability to frame references for the reader, making it clear that the evidence selected was an appropriate choice. By looking at the correspondence between the text and the citations, we can infer how well students understood the inclusion of their sources as choices. ${ }^{23}$ For example, there are times when the writer of a paper draws on information published by a government agency but simply refers to a news article that describes the report from the agency. Even if the parameters of the assignment or the goals of the paper do not require the student to track down the original report, the writer demonstrates a lack of understanding about the purposes for which he or she is using the evidence if the paper simply indicates the news source. Just noting the news source does not indicate to the 


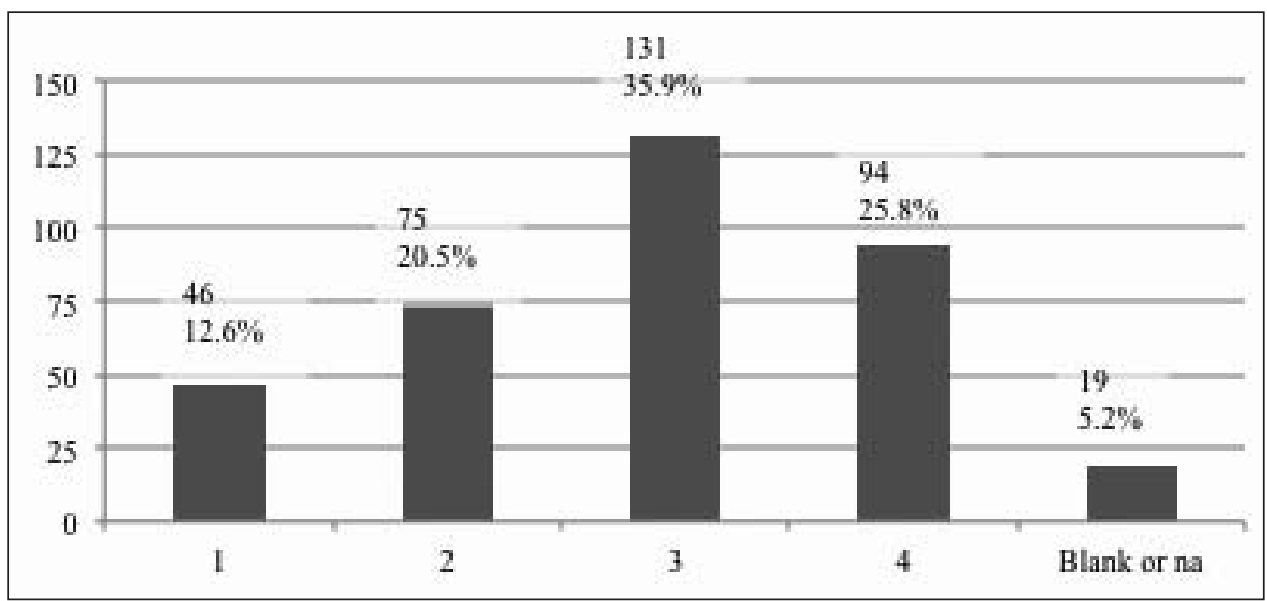

Figure 2. Disbribution of implementation of attribution scores

reader whether the particular article was an original news story, a press release from an agency, an opinion piece, or something else. Students could not have understood these problems and considerations if they thought that citing the secondary sources was effective or sufficiently informative.

\section{Communication}

All of the dimensions relate to communication in some way, but the communication dimension specifically helps us understand how well students incorporate the evidence they have selected into their prose. This dimension assesses the writers' abilities to synthesize and contextualize information, looking at how they frame direct and indirect quotations and how they refer to claims made in other sources. How well do they connect their own ideas to the ideas of others? Do they effectively articulate relevant contexts for their readers? Do they use information in the service of their own goals rather than yielding to the viewpoints of outsiders? ${ }^{24}$

The majority of sophomores are still developing the ability to use sources actively and effectively to support their own claims. They perform with slightly greater mastery here than in the other dimensions. Papers scored best in this dimension by a small margin, with an overall mean score of 2.86 out of 4 . Also, the greatest percentage of papers (28 percent) scored a 4 in this dimension, compared with 25.8 percent in attribution and 21.6 percent in evaluation. Even so, more than one-third of assessed papers failed to synthesize evidence in support of the argument, and nearly 8 percent offered no attempt to integrate sources. This dimension received the fewest reader comments, and unlike the other two dimensions, these comments were sometimes positive. "I know nothing about the subject matter but the writer's examples, references, and confidence are persuasive," one comment read, and "persuasive essay," another noted.

In strong papers, students maintained their own voices and goals as they integrated outside evidence. In weaker papers, "patch writing" and excessive citation signaled confusion about the sources used and the reason for drawing on the works of others in 


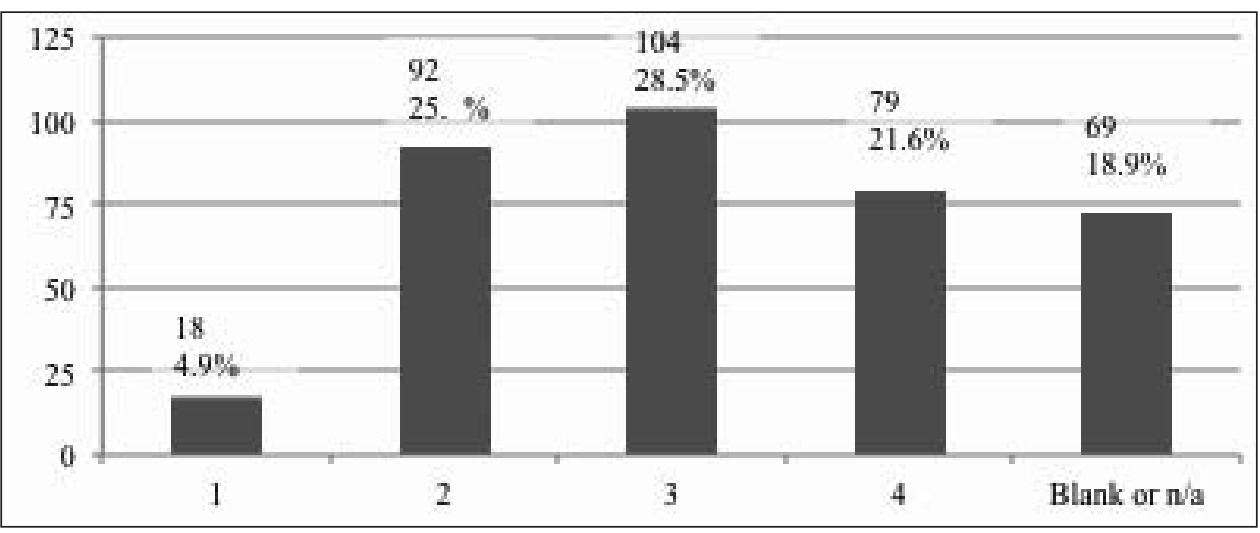

Figure 3. Distribution and evaluation of sources scores

the first place. ${ }^{25}$ Comments raised at the reading included: "[Sources] weakly synthesized into argument"; "difficult to know why he employs certain pieces of evidence"; "merely summarizing sources"; and "sources weren't used to argue point well." These are matters of framing and contextualization, but they signal deeper confusion about the role of sources in making claims.

\section{Teaching}

For instruction librarians, knowing more about what students do well and where they struggle directly informs classroom practice. While the ILSW project was not intended to formally assess our instruction, we have gained valuable insights that inform our practice. Overall, the results confirmed what we suspected. With mean scores between 2.79 and 2.86 out of 4 for all three dimensions, Carleton students generally possess information literacy skills that allow them to make and support claims at a level appropriate for sophomore work.

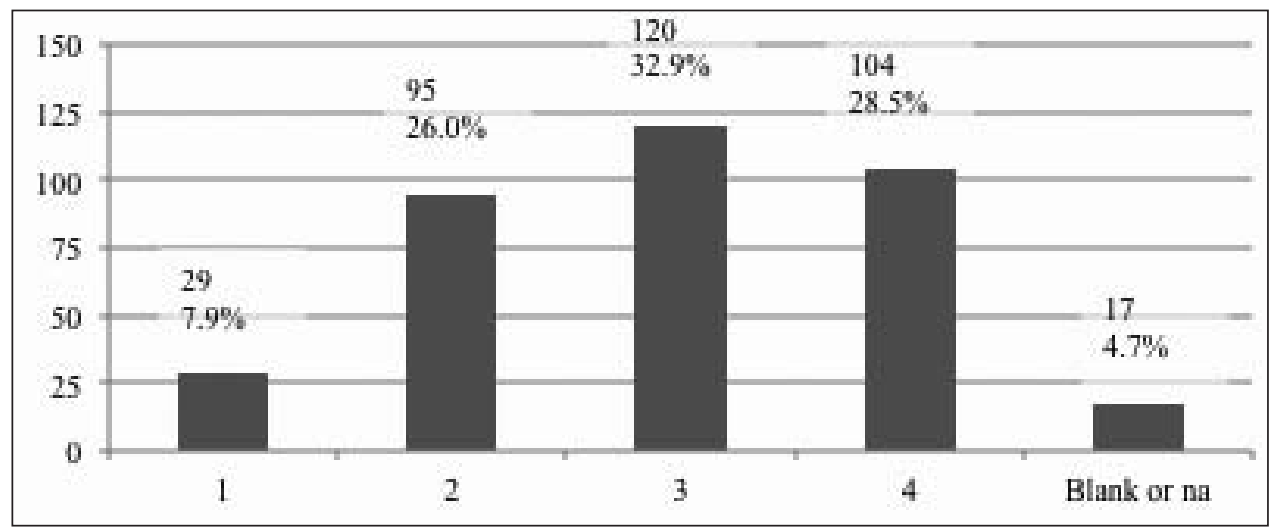

Figure 4. Distribution and communication of evidence scores 
Equally important, though, are the gaps and weaknesses that the ILSW project revealed in our students' competencies, as discussed earlier. These gaps have informed changes in how we teach and work with our students, helping us to prepare them more robustly for the demands of college work. In some cases, the modifications have been minor shifts in emphasis or explicitness. In other cases, the changes have been more fundamental. We have written previously about the ILSW project's impact on specific areas of our teaching. ${ }^{26}$ Broadly speaking, the project's findings have reinforced the need to emphasize information literacy as what Rolf Norgaard calls a "situated, process-oriented literacy relevant to a broad range of rhetorical and intellectual activities." 27 Because of this more nuanced view of our students' capabilities, we have adjusted our practice and begun to work more closely with a broader range of classroom faculty.

While not devaluing instruction about specific skills or resources, we now recognize that students need guidance about the role that evidence plays in their coursework and in

We now recognize that students need guidance about the role that evidence plays in their coursework and in their thinking. their thinking. Understanding why they are using supporting information of different kinds and in various ways will help them choose and use evidence more effectively. ${ }^{28}$ Quotations, paraphrases, and allusions are more than items to be packed into a paper to prove that the student has done the homework. They are powerful moves within what educators call a community of inquiry-a group, formal or informal, that engages in purposeful discourse to gain understanding and develop ideas that will lead to greater knowledge. Such references demonstrate awareness of the scholarly conversations already in play, engage the community's trust, and gesture toward previous thinkers both to carve out space for a new contribution and also to bolster the new writer's claim.

This broader understanding of information-literate habits of mind opens up new areas of the curriculum to library engagement. Many courses do not include a formal research project, but almost no course forges ahead without any context-building discussions or exercises. In discussing assignments

Creating the rubric and sharing our findings helped us not only to articulate a philosophy of information literacy but also to position ourselves as thoughtful contributors to instruction on campus. and learning goals with faculty, we now apply information literacy principles to a much broader range of intellectual activities and discourse. (This is especially useful in our work with faculty who are teaching the required first-year seminar, which requires an encounter with information literacy.) Sometimes explicit practice in building context prior to a class discussion suits the course. Other times, a full-blown research project is in order. Whichever the case, librarians now have the evidence needed to suggest instructional avenues with the confidence that a variety of activities will bolster students' habits of mind pertaining to the selec-

tion and use of information within a scholarly community. Our role as instructors can easily be overlooked, and thus our value to curricular development discussions is not 
always visible or appreciated. ${ }^{29}$ Creating the rubric and sharing our findings helped us not only to articulate a philosophy of information literacy but also to position ourselves as thoughtful contributors to instruction on campus.

\section{Program Development}

Unexpectedly, the discussions occasioned by the creation, revision, use, and reporting of the ILSW project have proved to be important outcomes of the project in their own right. In a large part, these productive and ongoing discussions are a result of the project's chosen assessment sample: students' completed written work for courses in various academic disciplines. Situating the ILSW project within disciplinary writing brings the world of information literacy directly into the world of the faculty, intertwining them in fundamental ways. For librarians, contextualizing information literacy within disciplines requires seeking out clues to information literacy habits of mind in less familiar territory. For faculty, this means looking in familiar territory for aspects of writing that the ILSW project perhaps defamiliarizes. Together with the formal presentations and reports on the project, the conversations resulting from this intertwining of worlds continue to nuance and inform our understanding and articulation of information literacy, of its place in various areas of scholarship, and of its importance to undergraduate writing in many genres.

Our ILSW project has enabled us to initiate meaningful conversations with faculty about information literacy. For many of our faculty, "information literacy" was a murky concept, and for a few it seemed entirely irrelevant. Too often it was associated strictly with the traditional undergraduate research paper. As we created and reported on the ILSW project, and especially during our 2011 reading with faculty, our conversations helped all of us integrate information literacy

For many of our faculty, "information literacy" was a murky concept, and for a few it seemed entirely irrelevant. more firmly within and across the disci-

plines. Perhaps the richest conversation in our 2011 reading with faculty concerned how (and if it were possible) to discern students' decisions about sources by looking at the finished writing. A number of questions arose about how much background knowledge of an academic discipline readers require to evaluate whether the paper writers have made wise decisions about sources. Through experimentation and conversation, it became apparent that, while readers from other fields may not recognize credible sources at a glance, successful papers include what Erin Daniels calls "credibility cues." ${ }^{30}$ That is, successful papers include some indication within the writing itself about the validity and relevance of the sources used, such as publication information, author credentials, use of a variety of sources rather than overreliance on one or two, clear differentiation between primary and secondary sources, and direct use of information from its original source rather than, for example, a newspaper report about the information. Justifying sources within the writing signals both a facility with the process of evaluation and also a well-developed awareness of the role that credible sources play in the support of claims. 
In addition to these conversations, the rubric creation and findings provided an impetus and context in which to share our philosophy of information literacy and to discuss it more formally with the campus community through a variety of presentations and workshops. At Carleton, such faculty development opportunities are critical and meaningful ways to participate in curriculum development. ${ }^{31}$ Because of this, articulating our deepened understanding of information literacy, its relevance, and its contribution to work in various academic disciplines is a key part of our information literacy program.

This stronger information literacy program expands on our previous efforts in two key ways: locating information literacy explicitly within the curriculum as a whole and redefining information literacy as a habit of mind. These two outcomes, explained in greater detail later, have enriched our work and our instruction far more than a simple survey of student skills could have done.

We now know in far more concrete terms than before that finding, evaluating, and employing sources are inextricably linked. Of course, the existence of this linkage is not a new concept in the library literature. In the early 1990s, Barbara Fister noted that the entire process of research is a rhetorical activity

We now know in far more concrete terms than before that finding, evaluating, and employing sources are inextricably linked. in which everything from search terms to sources to writing are understood as part of scholarly discourse. ${ }^{32}$ In the early 2000s, Rolf Norgaard argued that writing is the process by which students make meaning from disparate texts. ${ }^{33}$ And in 2010, Annemaree Lloyd went even further, asserting that information by itself is meaningless: "Information needs to be situated within a context in order for it to have meaning and to be used in meaningful ways by people ... It is through the situated dialogic relationship that information is transformed into knowledge." ${ }^{34}$ Information literacy, then, is necessary to many kinds

Information literacy is, by necessity, shaped by context and intent. of critical thinking, and as such is an important component of an undergraduate curriculum. ${ }^{35} \mathrm{~A}$ cornerstone of our information literacy program is that information literacy is not a stand-alone set of skills and aptitudes. Instead, information literacy is, as Norgaard says, "always an embedded or situated

cultural practice." ${ }^{36}$ Information literacy is, by necessity, shaped by context and intent. ${ }^{37}$ We cannot think of it or teach it as a fully discrete set of abilities. We cannot pull it out, tinker with it, and give it back to students.

Rather than being a set of discrete skills, information literacy is a habit of mind that, once developed, will prompt students to discover gaps in their knowledge, act intelligently to fill those gaps, and think critically about information they find..$^{38}$ Over time, encounters with problems demanding information literacy will strengthen those habits of thinking until students exhibit the habits regardless of direct prompting via assignment or instruction. That process is what makes for truly adept lifelong learners, and Wiggins, in his landmark book on assessment and critical thinking, writes, "Capacity for autonomous learning and a thirst for unending education are more important than accurate recall or simplistic application of the particular knowledge taught." ${ }^{39}$ And while 
lifelong learning has a long-standing tradition as a central goal in higher education, we hope that information-literate habits of mind can enable students to reach even beyond the ability to learn. As Norgaard asserts, information literacy "can become an inventional resource for the student, not merely a resource for supporting what has already been invented" (emphasis added). ${ }^{40}$ In short, without dismissing the importance of skills, we aim to foster intellectual habits as they relate to engagement with information. Teaching students that research is entwined with communication goals means teaching information literacy as active participation in scholarly conversation and knowledge production.

The formal and informal conversations occasioned by the development and use of the ILSW rubric have created an opportunity for faculty and librarians to consider the concept of information literacy in deeper and more nuanced ways than if we or the college administration had simply disseminated a completed, polished assessment report. By grappling with questions about attribution, evaluation, and communication together, faculty and librarians partnered to define information literacy on our campus. By wrestling with these questions as a campus rather than as individual departments, we have begun setting community-wide expectations and have created greater opportunities for buy-in, often from unexpected quarters. The resulting rubric resonates more widely with our campus community than, for example, the ACRL Information Literacy Standards have done. We have translated the standards, alongside other professional values, into language that faculty value. ${ }^{41}$ Since the inception of the project, we have received requests from faculty and from departments to use our rubric in courses and in departmental assessment projects. These requests signal that the rubric fills a need and resonates with teaching faculty across the campus.

\section{Conclusion}

After developing the rubric, reading hundreds of papers, and sharing the rubric across the campus, our program is better integrated with campus-wide goals, opportunities for information literacy instruction have opened up, and we have begun the long process of arriving at a shared understanding of information literacy on campus. Our project, its findings, and the campus discussions around it have given us principles and evidence that allow us to participate effectively in campuswide assessment and curricular conversations. They have also helped us engage earlier and more fully in course and assignment development with faculty. ${ }^{42}$ The definition of information literacy as it is embodied in our rubric highlights the ways in which information literacy is an integral part of much of the college curriculum.

We believe our findings have implications for other academic librarians. Based on our experience with this project, five themes emerge. First, assess-

While developing a rubric
that furthers program goals
can be a painstaking and
complicated process, it is
worth the investment of
time and energy.
ment can and should be deeply integrated within campus culture to garner meaningful and sustainable outcomes. Second, understanding information literacy as intellectual habits of mind enables librarians to discern and assess complex relationships between 
argument and information. Third, our rubric successfully assesses papers for these relationships and can serve as a model for other librarians to adapt and use at their institutions. Fourth, while developing a rubric that furthers program goals can be a painstaking and complicated process, it is worth the investment of time and energy. Finally, an assessment project can serve to launch faculty-librarian conversations around information literacy that strengthen programs far beyond reporting simple anecdotes or statistics about student skills.

When we first conceived this assessment project, we hoped to learn something useful about our students' abilities, and we have. What we did not anticipate were the many ways in which this project would instigate conversation and change on campus. To develop a rubric, we first had to clearly articulate how information literacy makes itself evident in undergraduate papers, which in turn taught us to think about how infor-

Information literacy is more than a
rote set of skills; it is a critical habit
of mind, integral to disciplinary
practice and inquiry.
mation literacy is embedded in academic writing in general. Our rubric reflects the understanding we reached. Information literacy is more than a rote set of skills; it is a critical habit of mind, integral to disciplinary practice and inquiry. We learned that students by and large could perform basic information literacy practices but that they did not yet demonstrate habituated mastery of information-literate thought. And as understanding of information literacy on our campus grows deeper and more complex, new ways to converse with faculty about pedagogy open up. Thus assessment—-that seemingly dull and simplistic task—has proved to be engaging, complex, and useful for our library.

\section{Acknowledgments}

The authors thank their departmental colleagues, who are full partners in all of the work and thinking presented here. We would also like to thank our faculty and staff colleagues on campus for their vital support and feedback.

Iris Jastram, Danya Leebaw, and Heather Tompkins are reference and instruction librarians in the Laurence McKinley Gould Library at Carleton College in Northfield, MN. Heather Tompkins is also the project lead for ILSW. Jastram may be reached by e-mail at: ijastram@carleton.edu. E-mail to Leebaw may be sent to: dleebaw@carleton.edu. Tompkins may be written to at: htompkin@ carleton.edu. 


\section{Appendix: Information Literacy in Student Writing Rubric}

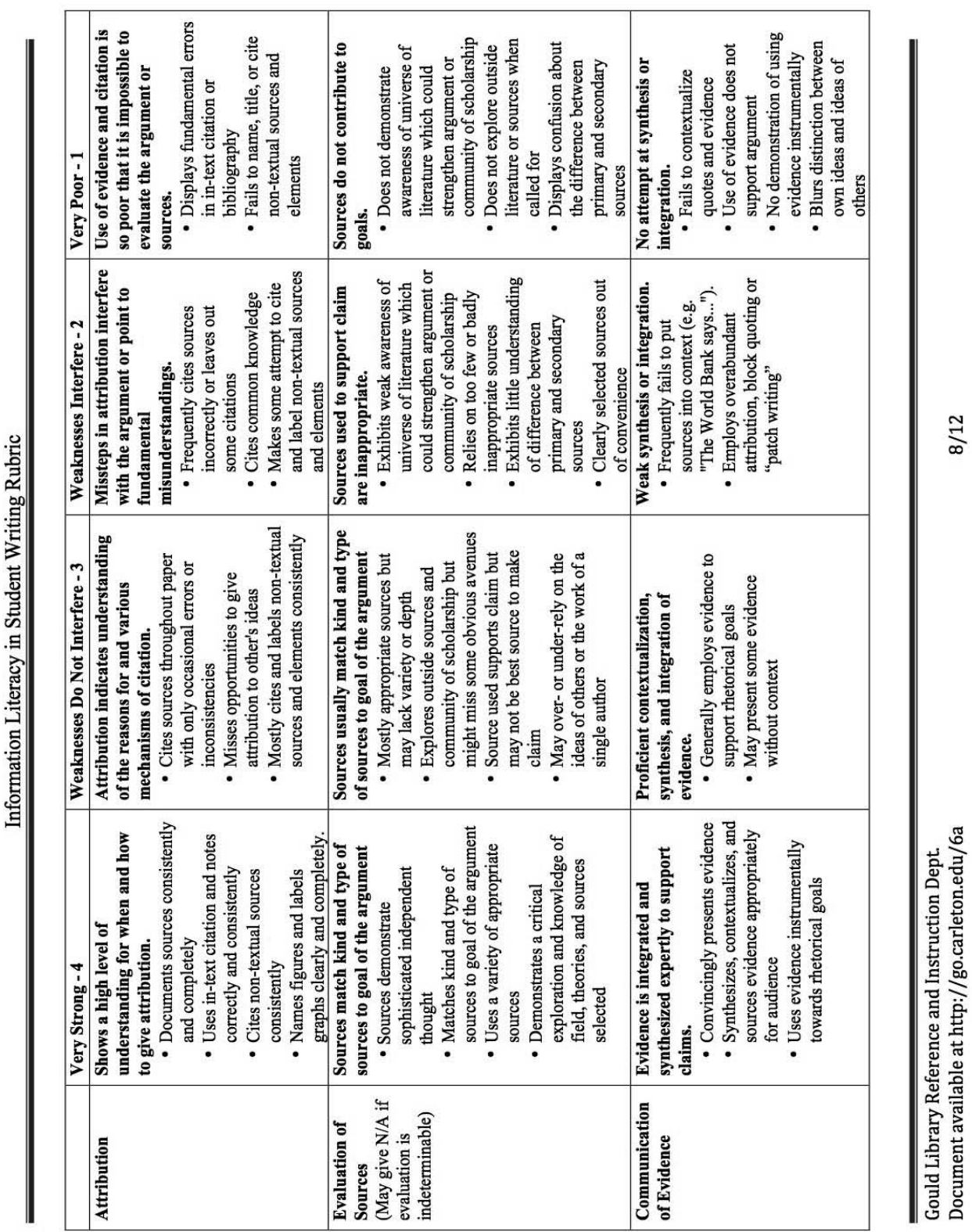



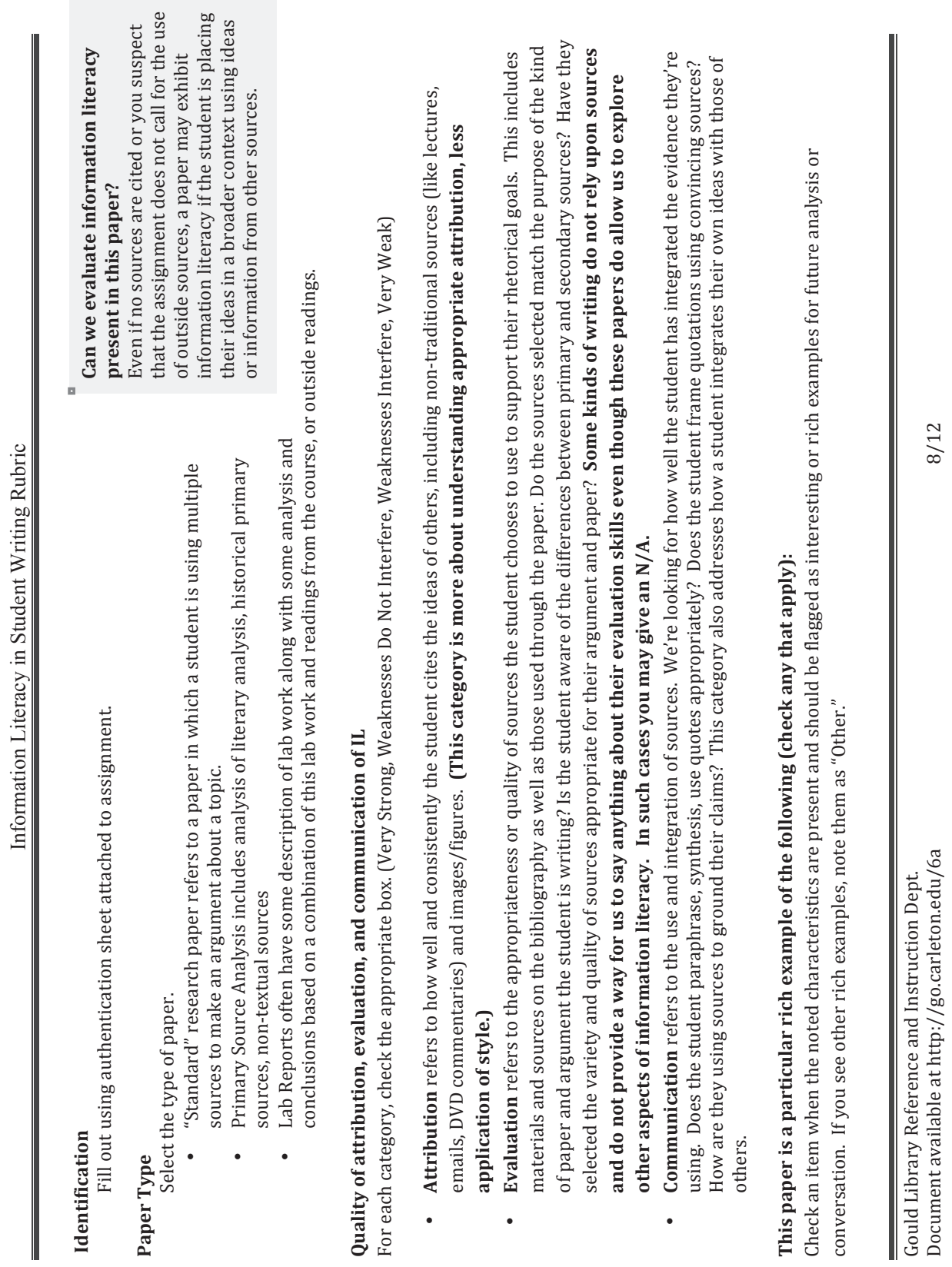


\section{Identification}

Student number

Course number and professor

Documented Sources designation $\mathrm{Y} / \mathrm{N}$

Reader ID

Term/year

(a)

Paper Type

Standard Research Paper

Lab Report

Primary Source Analysis

Other

Could not evaluate
information literacy in
this paper? Check the
box and you're done.

Quality of attribution, evaluation, and communication of IL (see rubric for details):

\begin{tabular}{|l|l|l|l|l|}
\hline & Very Strong & $\begin{array}{l}\text { Weaknesses do } \\
\text { not Interfere }\end{array}$ & $\begin{array}{l}\text { Weaknesses } \\
\text { Interfere }\end{array}$ & Very Poor \\
\hline Attribution & & & & \\
\hline $\begin{array}{l}\text { Evaluation of } \\
\text { Sources (or N/A) }\end{array}$ & & & & \\
\hline $\begin{array}{l}\text { Communication } \\
\text { of Evidence }\end{array}$ & & & & \\
\hline
\end{tabular}

\section{OPTIONAL}

This paper is a particularly rich example of the following (check any that apply)

$\square$ Documentation designation wrong

$\square$ Egregious errors in bibliography, in-text citations, notes

$\square$ Little or no attribution of non-textual elements

Over/Under cited claims $\square$ Sources lack breadth or depth

$\square$ Inappropriate source(s) used to support claim

$\square$ Sources not integrated or synthesized $\square$ Other

Elaboration (opt.) 


\section{Notes}

1. Carol Rutz and Jacqulyn Lauer-Glebov, "Assessment and Innovation: One Darn Thing Leads to Another," Assessing Writing 10, 2 (2005): 85. Rutz and Lauer-Glebov talk about how faculty value inquisitiveness and autonomy, and argue that activities that strengthen campus-wide goals flourish best when they respect these values.

2. See, for example, the language of the required elements in our first-year seminars, which states that students in these seminars should "develop liberal arts habits of mind-critical thinking, collaboration with peers, intellectual independence, and reflective learning." Carleton College, “Graduation Requirements," accessed October 10, 2013, http: / / apps. carleton.edu/academics/liberalarts/ requirements/.

3. The first learning objective for the quantitative reasoning encounters states that graduating students should "possess the habit of mind to consider what numerical evidence might add to the analysis of a problem." Ibid.

4. Rolf Norgaard, "Writing Information Literacy: Contributions to a Concept," Reference and User Services Quarterly 43, 2 (2003): 125.

5. Nathan D. Grawe, Neil S. Lutsky, and Christopher J. Tassava, "A Rubric for Assessing Quantitative Reasoning in Written Arguments," Numeracy 3, 1 (2010).

6. Presidential Committee on Information Literacy: Final Report (Chicago: American Library Association, 1989), accessed October 9, 2013, http: / / www.ala.org/acrl/publications / whitepapers/presidential.

7. Association of College and Research Libraries (ACRL), Information Literacy Competency Standards for Higher Education (2011), accessed October 9, 2013, http: / / www.ala.org/acrl/ standards/informationliteracycompetency.

8. Lorrie A. Knight, "Using Rubrics to Assess Information Literacy," Reference Services Review 34, 1 (2006): 43.

9. Bonnie Gratch Lindauer introduces the motivating forces behind information literacy assessment in "The Three Arenas of Information Literacy Assessment," Reference and User Services Quarterly 44, 2 (2004): 122.

10. The Rochester project, headed by Nancy Fried Foster, is a particularly good complement for our Information Literacy in Student Writing (ILSW) project because both look closely at student work in situ, learning about complex environments and processes in an authentic context. For information on Project Information Literacy and Project SAILS (Standardized Assessment of Information Literacy Skills), see Project Information Literacy, accessed October 9, 2013, http: / / projectinfolit.org/about/; Project SAILS, "Standardized Assessment of Information Literacy Skills," accessed October 9, 2013, http: / / www. projectsails.org.

11. For more on rubrics and how they function in information literacy assessment see Debra Gilchrist and Megan Oakleaf, "An Essential Partner: The Librarian's Role in Student Learning Assessment," National Institute for Learning Outcomes Assessment-Occasional Paper \#14 (April 2012). Oakleaf also discusses the qualities of strong rubrics and the time involved to develop those rubrics in Megan Oakleaf, "Dangers and Opportunities: A Conceptual Map of Information Literacy Assessment Approaches," portal: Libraries and the Academy 8, 3 (October 2008).

12. Karen R. Diller and Sue F. Phelps, "Learning Outcomes, Portfolios, and Rubrics, Oh My! Authentic Assessment of an Information Literacy Program," portal: Libraries and the Academy 8, 1 (January 2008); Knight, "Using Rubrics to Assess Information Literacy," 45-46; Sue Samson, "Information Literacy Learning Outcomes and Student Success," Journal of Academic Librarianship 36, 3 (2010); Davida Scharf, Norbert Elliot, Heather A. Huey, Vladimir Briller, and Kamal Joshi, "Direct Assessment of Information Literacy Using Writing Portfolios," Journal of Academic Librarianship 33, 4 (2007).

13. Diller and Phelps, "Learning Outcomes, Portfolios, and Rubrics, Oh My!"; Mark Emmons and Wanda Martin, "Engaging Conversation: Evaluating the Contribution of Library 
Instruction to the Quality of Student Research," College E Research Libraries 63, 6 (2002); Megan Oakleaf, Michelle S. Millet, and Leah Kraus, "All Together Now: Getting Faculty, Administrators, and Staff Engaged in Information Literacy Assessment," portal: Libraries and the Academy 11, 3 (July 2011); Scharf et al., "Direct Assessment of Information Literacy Using Writing Portfolios."

14. Findings in this paragraph synthesized from Elizabeth Choinski, Amy E. Mark, and Missy Murphey, "Assessment with Rubrics: An Efficient and Objective Means of Assessing Student Outcomes in an Information Resources Class," portal: Libraries and the Academy 3, 4 (October 2003); Emmons and Martin, "Engaging Conversation: Evaluating the Contribution of Library Instruction to the Quality of Student Research; Scharf et al., "Direct Assessment of Information Literacy Using Writing Portfolios."

15. Oakleaf, "Dangers and Opportunities"; Grant P. Wiggins, Assessing Student Performance (San Francisco: Jossey-Bass, 1993).

16. Wiggins, Assessing Student Performance, 36.

17. Using a community rather than individuals as the focus of analysis is an emerging methodology in library and information science. Annemaree Lloyd explains that information behavior research is common in the field and says, "While information behaviour research tends to focus on the individual, information practice research is more focused towards the domain or the community as the unit of analysis." Annemaree Lloyd, Information Literacy Landscapes: Information Literacy in Education, Workplace, and Everyday Contexts (Oxford: Chandos, 2010), 23.

18. Danya Leebaw, Kristin Partlo, and Heather Tompkins, "'How Is This Different from Critical Thinking?' The Risks and Rewards of Deepening Faculty Involvement in an Information Literacy Rubric," in ACRL 2013 (Indianapolis: Association of College and Research Libraries [ACRL], 2013), 274-77, http: / / www.ala.org/acrl/sites/ala.org.acrl/files / content/conferences/confsandpreconfs/2013/papers / LeebawPartloTompkins_HowIsThis. pdf.

19. For more on authentic assessment and using rubrics to assess skills not explicitly listed in assignments, see Grawe, Lutsky, and Tassava, "A Rubric for Assessing Quantitative Reasoning in Written Arguments."

20. W. James Popham discusses balancing generalized and specific criteria and the risks of "equating the test of the skill with the skill itself" in "What's Wrong-and What's Rightwith Rubrics," Educational Leadership 55, 2 (1997).

21. Megan Oakleaf, "Are They Learning? Are We? Learning Outcomes and the Academic Library," Library Quarterly 81, 1 (2011): 63.

22. Erin Daniels, "Using a Targeted Rubric to Deepen Direct Assessment of College Students' Abilities to Evaluate the Credibility of Sources," College \& Undergraduate Libraries 17, 1 (2010); Britt A. Fagerheim and Flora G. Shrode, "Information Literacy Rubrics Within the Disciplines," Communications in Information Literacy 3, 2 (2009).

23. Daniels, "Using a Targeted Rubric to Deepen Direct Assessment of College Students” Abilities to Evaluate the Credibility of Sources."

24. These are key goals for academic work, but they are also important for college graduates entering the workforce. New research from Project Information Literacy finds that employers need college graduates who are adept at synthesis, and that they are disappointed when graduates get "stuck in the mud trying to figure out what [the information they gather] means." Alison J. Head, Learning Curve: How College Graduates Solve Information Problems Once They Join the Workplace (2012), 13, http: / / projectinfolit.org/ pdfs/PIL_fall2012_workplaceStudy_FullReport.pdf.

25. "Patch writing" refers to the practice of gathering verbatim passages from various sources and then piecing them together, much like a patchwork quilt, with connecting words and sentences. The term was coined by Rebecca Moore Howard in her 1999 work Standing in the Shadow of Giants: Plagiarists, Authors, Collaborators, Perspectives on Writing: Theory, Research, and Practice (Stamford, CT: Ablex, 1999). 
26. Iris Jastram, Danya Leebaw, and Heather Tompkins, "CSI(L) Carleton: Forensic Librarians and Reflective Practices," accessed October 10, 2013, http: / / www. inthelibrarywiththeleadpipe.org/2011 / csil-carleton-forensic-librarians-and-reflectivepractices/.

27. Norgaard, "Writing Information Literacy," 125.

28. See Joseph Bizup, "BEAM: A Rhetorical Vocabulary for Teaching Research-Based Writing," Rhetoric Review 27, 1 (2008).

29. Barbara D'Angelo and Barry Maid note that, without a disciplinary home on campus, librarians often cannot directly impact curriculum development. See Barbara J. D. D'Angelo and Barry M. Maid, "Moving Beyond Definitions: Implementing Information Literacy Across the Curriculum," Journal of Academic Librarianship 30, 3 (2004): 213. Parker Palmer explores how institutional resistance to change can discourage or energize reformers in Parker J. Palmer, The Courage to Teach: Exploring the Inner Landscape of a Teacher's Life (San Francisco: Jossey-Bass, 1998), 163-83.

30. Daniels, "Using a Targeted Rubric to Deepen Direct Assessment of College Students' Abilities to Evaluate the Credibility of Sources," 35.

31. For an excellent discussion on librarians' positions as outsiders on their campuses and how this can empower them, see Maria Accardi, "Teaching Against the Grain: Critical Assessment in the Library Classroom" (Duluth, MN: Library Juice Press, 2010). For thoughts on librarians as "discourse mediators," see Michelle Holschuh Simmons, "Librarians as Disciplinary Discourse Mediators: Using Genre Theory to Move Toward Critical Information Literacy," portal: Libraries and the Academy 5, 3 (October 2005).

32. Barbara Fister, "Teaching the Rhetorical Dimensions of Research," Research Strategies 11, 4 (1993).

33. Norgaard, "Writing Information Literacy."

34. Lloyd, Information Literacy Landscapes, 12.

35. For a review of critical thinking components woven into library instruction, see Erin L. Ellis and Kara M. Whatley, "The Evolution of Critical Thinking Skills in Library Instruction, 1986-2006," College E Undergraduate Libraries 15, 1-2 (2008).

36. Norgaard, "Writing Information Literacy," 126.

37. See Christine Bruce and Hilary Hughes, "Informed Learning: A Pedagogical Construct Attending Simultaneously to Information Use and Learning," Library E Information Science Research 32, 4 (2010); Lloyd, Information Literacy Landscapes; Troy A. Swanson, "A Radical Step: Implementing a Critical Information Literacy Model," portal: Libraries and the Academy 4, 2 (April 2004); Fister, "Teaching the Rhetorical Dimensions of Research."

38. See James Elmborg, "Critical Information Literacy: Definitions and Challenges," in Transforming Information Literacy Programs: Intersecting Frontiers of Self, Library Culture, and Campus Community, ed. Carroll Wetzel Wilkinson and Courtney Bruch, 75-95 (Chicago: ACRL, 2012); Gould Library Reference \& Instruction Department, Carleton College, "Information Literacy at Carleton: Six Critical Habits of Mind," 2008, http: / / apps.carleton. edu/campus / library / assets / Information_Literacy_at_Carleton.pdf.

39. Wiggins, Assessing Student Performance, 34.

40. Norgaard, “Writing Information Literacy," 129.

41. Barbara D'Angelo, "Student Learning and Workplace IL: A Case Study," Library Trends 60, 3 (2012): 646. For a rhetorician's perspective on the role of sources in writing, see Bizup, "BEAM."

42. Oakleaf writes, "Although the Standards articulate the information literacy skills students need to acquire during their higher education experience, many faculty and institutional administrators consider them library-centric standards. Therefore, to create value in the minds of students, faculty, and administrators, libraries need to establish their value in terms of academic departments and institutional teaching goals by augmenting the Standards with broader views, especially when communication outside the library administration and within a campus-wide context." Oakleaf, "Are They Learning? Are We?" 63. 